doi.org/ 10.51891/rease.v8ir.3935

\title{
NOÇÕES DE DIREITO CONSTITUCIONAL NO ENSINO FUNDAMENTAL II: UMDEVER DO ESTADO DEMOCRÁTICO DE DIREITO
}

\author{
NOTIONS OF CONSTITUTIONAL LAW IN ELEMENTARY EDUCATION II: A \\ DUTY OF THE DEMOCRATIC STATE OF LAW
}

\author{
Domingos Carlos José Pereira ${ }^{1}$ \\ Igor da Silva Rosa ${ }^{2}$
}

\begin{abstract}
RESUMO: O presente artigo tem como objetivo mostrar a sociedade e nossos representantes legislativos a importância do Direito Constitucional no Ensino Fundamental II. Em um Estado democrático de direito,em que o princípio basilar é a legalidade, nada mais coerente que ensinar o Direito Constitucional na educação básica de nosso País. Nesse escopo, em todo o território nacional os direitos individuais, coletivos e sociais são suprimidos, diuturnamente, exigindo assim, serem abordados, de forma ampla e didática, para cada idade correspondente ao ano que o discente está cursando. Um jovem que conhece a estrutura fundamental da Administração Pública, os limites dos poderes da República e, principalmente, seus direitos e deveres tende a exercer sua cidadania com mais consciência e responsabilidade. A formação do professor deve ser específica diante da relevância e complexidade do tema. Nessa vertente, ao iniciar o Ensino Fundamental II, a escola deve tratar de forma pedagógica o estudo mais básico da nossa Lei Maior, como por exemplo, cidadania, os objetivos da República Federativa do Brasil, seus fundamentos e, sobretudo, os direitos e garantias fundament ais. Nessa perspectiva, aos dezesseis (I6) anos de idade, quando o jovem está apto a exercer seu direito de cidadão já terá quatro (4) anos de estudo da referida disciplina, o que lhe proporcionará, de acordo comseu conhecimento, fazer uma melhor escolha para representá-lo tanto no Executivo como também noLegislativo federal, estadual/distrital e municipal. Dessa forma, podemos melhorar a médio e longo prazo nossa representatividade na Administração Pública, através do desenvolvimento crítico e o espírito de coletividade das futuras gerações.
\end{abstract}

Palavras-chave: Direito Constitucional. Estado Democrático de Direito. Cidadania. Educação. Escola.

ABSTRACT: The main purpose of this current article is to show to our society and our legislative representatives theimportance of Constitutional Law in Elementary School II. In our Democratic State of Law, where the essential principle is legality, there is nothing more logical and important than teaching Constitutional law in basic education of our country. Under these circumstances, to be approached in a widely and didactic way for each age corresponding to the year the student is attending to. A young student who knows the fundamental structure of Public Administration and the boundaries of the powers of the Republic, and especially its rights and duties, tends to put in practice their social function with more awareness and responsibility. Teacher training must be specific, and focuses on the relevance and complexity of the topic. At this way, when a student begins Elementary School II, school mustpedagogically know how to deal with the most basic study of our Major Law, such as citizenship, the objectives of the Federative Republic of Brazil, its foundations and especially the fundamental rights andguarantees. Following this thought, at sixteen (I6) years of age, when the young person is able to exercise their right as a citizen, they will already have four (4) years of study at the target subject. Which will allow students, according to their knowledge, to make a better choice to represent them both in theExecutive and in the Federal, State and Municipal Legislative branches. At this way, we can improve our representation in the Public Administration in the medium and long period of time, using critical development and the collective spirit of future generations.

Keywords: Constitutional right. Democratic state. Citizenship. Education. School.

I Servidor público da Secretaria de Estado de Educação do Distrito Federal. Formação: Gestor público pela Faculdade Anhanguera - UNIDER. Pós-graduado em gestão escolar. Bacharel em direito pela UDF - Centro Universitário do Distrito Federal.

2 Servidor público da secretaria de estado de educação do distrito federal. Bacharel em direito pela UDF - Centro Universitário do Distrito Federal. 


\section{INTRODUÇÃO}

Em o5 de Outubro de 1988, a Assembleia Constituinte promulgou nossa Lei Maior, a Constituição da República Federativa do Brasil - CRFB/88, conhecida também como a Constituição Cidadã, tornamos um Estado Democrático de Direito e,até nos dias atuais, ou seja, 33 anos após a sua promulgação, se perguntarmos qual o significado desse modelo governamental, muitos terão dificuldade de esclarecer. Por isso, a intenção deste artigo é mostrar ao leitor a importância do Direito Constitucional no Ensino fundamental II na Educação básica de nosso País.

O conhecimento dos direitos e deveres por parte dos cidadãos é fundamental para o desenvolvimento de nosso País, por isso, o foco em mostrar a importância do Direito constitucional no ensino fundamental II. Neste contexto, implementar essa disciplina na fase fértil de formação do caráter social e moral dos jovens compretensão de melhorar, de forma progressivamente, tanto a formação profissional, como também a cidadania desse público, em consequência disso, proporcionará uma melhor escolha de nossos representantes.

Cabe asseverar que com o Estado Democrático de Direito surgiram direitos e 1060 deveres de todos os cidadãos, que serão abordados no decorrer deste artigo. Ressaltam-se que, desde a promulgação da $\mathrm{CRFB} / 88$, os jovens conquistaram o direito de votar aos dezesseis anos. Com o lema "chegou a nossa vez, voto aos dezesseis" em 1980, articulados com entidades como a União Brasileira dos Estudantes Secundaristas - UBES e União Brasileira dos Estudantes - UNE. Porém, de lá para cá, a juventude está cada vez mais desinteressada em participar de forma ativa das escolhas eleitorais e de exercer seu papel como cidadão em uma democracia representativa e participativa.

É notório que faltam políticas públicas efetivas que mostrem a esse público a importância do processo eleitoral, e o papel de um cidadão. Nada mais racional mostrar que através do Ensino do Direito Constitucional, nas Escolas Públicas privadas, podemos envolver essas crianças e adolescentes nesse processo de forma correta, isto é, através do conhecimento, proporcionando a esses jovens o espírito coletivo de entender qual seu papel como cidadão, cobrar os deveres de seus representantes, corrigir através dos

${ }^{3}$ Disponível em: https://ubes.org.br/2017/desde-1988-voto-aos-16-anos-e-conquista-da-juventude/ (Acesso em I8/10/202I) 
instrumentos da democracia, como por exemplo, voto direto, iniciativa popular, plebiscito, referendo, audiência pública, consulta pública, entre outros, ou seja, despertar na juventude o papel de ser um fiscal dos gestores públicos, exigir direitos por omissão do poder público, propiciar meios que viabilizem a justiça social e igualdade entre os indivíduos.

Nessa perspectiva, há alguns questionamentos a serem enfrentados no desenvolvimento deste trabalho, quais sejam: qual o conceito de Estado Democrático de Direito, definição de cidadania, há limites impostos pela CRFB/88 em incluir um novo componente curricular na base nacional? O que diz a Lei 9394/96 (Lei de Diretrize Bases da Educação Nacional - LDB)? os jovens de i6 (dezesseis) anos atualmente estão preparados para escolherem seus representantes? quais as vantagens na formação dos jovens com a implantação do Direito Constitucional no Ensino Fundamental II na educação brasileira? qual a importância do professor nesseprocesso de formação?

Para a produção deste artigo, foi utilizado o método bibliográfico tanto por meios físicos como também virtuais, com uso da legislação da educação brasileira, Constituição Federal, artigos virtuais, físicos, trechos de matérias em jornais, doutrina, jurisprudência e matérias em sites na internet.

\section{DO ESTADO DEMOCRÁTICO DE DIREITO}

Segundo o site planalto, a origem do conceito de Estado Democrático de Direito surgiu, na Grécia Antiga, junto ao conceito de cidadão ativo, isto é, "quando surgiu a democracia direta. O Cidadão ativo era aquele que poderia exercer poderes políticos. Naquela época, eram apenas homens livres, com posses e que se reuniam em praçaspúblicas e decidiam os rumos das cidades-estados" 4 .

De acordo com o professor de direito constitucional ${ }^{5}$ Edgard Leite, para entender o conceito de Estado democrático, é preciso entender o conceito de "Democrático" que, em suas palavras, concentra-se todo seu significado na própria expressão. Em suma, ele define o Estado Democrático de Direito como: "são as leis criadas pelo povo e para o povo, respeitando a dignidade da pessoa humana”.

O professor José Afonso da Silva nos esclarece também de forma mais didática:

O Estado Democrático se funda no princípio da soberania popular que 'impõe a

${ }^{4}$ Disponível em: $<$ http://www2.planalto.gov.br/mandatomicheltemer/acompanhe-

planalto/noticias/2018/ro/entenda-o-que-e-o-estado-democratico-de-direito.> (Acesso em 29/10/2021).

${ }^{5}$ SILVA, José Afonso da. Curso de Direito Constitucional Positivo. 28를 Ed. Brasil: Malheiros, 2007, p 66 
participação efetiva e operante do povo na coisa pública, participação que não se exaure, como veremos, na simples formação das instituições representativas, que constituem um estágio da evolução do Estado Democrático, mas não o seu completo desenvolvimento.

Diante deste conceito, percebe-se a importância de ser um Estado Democrático de Direito, estabelecendo a participação efetiva do povo, tão relevante que o legislador constituinte, por medo de esquecerem, já positivou primordialmente na Lei Maior de nossa República, Art. Ioㅗ § único da $\mathrm{CRFB} / 88^{6}$. Aqui vale reforçar que se os cidadãos dês conhecem os instrumentos da democracia, tais instrumentos não servem para nada, o que nos reforça que há necessidade de a escola ser protagonista dadisseminação dos institutos constitucionais que cada um de nós temos para aperfeiçoar nossa democracia.

O site "Mundo da Educação Uol” nos define também informando as virtudesque ratificam os princípios basilares da Constituição Cidadã:

O Estado Democrático de Direito é aquele em que o poder do Estado é limitado pelos direitos dos cidadãos. Sua finalidade é coibir abusos do aparato estatal para com os indivíduos. Os direitos fundamentais conferem autonomia e liberdade aos indivíduos nas suas atividades cotidianas e limitam o poder do Estado sobre elas ${ }^{7}$.

Diante disso, não faz sentido um Estado Democrático de Direito não ensinar as finalidades da democracia para seus concidadãos exercerem de forma ativa sua função, como mencionado na introdução deste artigo, que grande parte dos brasileiros desconhecem a importância de suas participações no processo democrático representativo e participativa de nosso país. E é por esse e tantos outros motivos queconsideramos relevante e oportuna a inclusão da disciplina Direito Constitucional na base curricular nacional.

\section{CIDADANIA}

$\mathrm{Na}$ Grécia antiga, só participava das decisões das polis era quem tinha poder aquisitivo, ficavam de fora aqueles que não eram cidadãos. Nota-se que era bastanterestritivo o sistema democrático da Grécia antiga, "século V. a. C., O cidadão tinha deter algum status na polis para participar da vida política ${ }^{8}$,

A cidadania tem conceitos vastos e, de acordo com a maioria dos Autores

\footnotetext{
${ }^{6}$ Disponível em: http://www.planalto.gov.br/ccivil_03/constituicao/constituicao.htm, Art. Io A República Federativa do Brasil, formada pela união indissolúvel dos Estados e Municípios e do Distrito Federal,constitui-se em Estado Democrático de Direito e tem como fundamentos: Parágrafo único. Todo o poder emana do povo, que o exerce por meio de representantes eleitos ou diretamente, nos termos destaConstituição. (acesso em 1o/ro/202I).

${ }^{7}$ Disponível em:http://gi.globo.com/sp/vale-do-paraiba-regiao/o-futuro-das-cidades/2015/ (acessoem:10/o9/2021)

${ }^{8}$ GOYARD-FABRE, Simone. o que é Democracia? São Paulo, 2003, p. 14
} 
pesquisados, não há um conceito fechado. Nesse sentido, explanaremos alguns conceitos, os quais julgamos de mais fácil entendimento, com relação esse tema.

Nas palavras de Liszt vieira (2000, pg. 22), um dos primeiros a conceituar cidadania foi Thomas Humphrey Marshall e ele divide em 3 (três) vertentes, quais sejam: o conceito Civil, política e social que, segundo o autor, os direitos civis são conquistados no século XVIII, os direitos políticos no século XIX, por fim, os direitos sociais no século XX. Na sua visão, os direitos civis: estão relacionados com as liberdades individuais, também conhecido como direitos de primeira dimensão; os direitos políticos: considerados também primeira dimensão, liberdades individuais e coletivas, de reunião, associação, sufrágio universal, direito do voto, direitos políticos; já os direitos sociais: são de segunda dimensão referem se aos mesmos positivados em nossa Constituição, ou seja, educação, saúde, alimentação, trabalho, a moradia, entre outros.

Diante deste contexto, é possível inferir que a história nos ensina que as sociedades são dinâmicas e precisam de adequações com o passar dos tempos. Nossa necessidade nesse momento, diante da realidade apresentada pelos jovens, é orientá-los e instruí-los a exercerem plenamente seus direitos e deveres, para que o futuro seja diferente em termos de evolução.

\section{O QUE DIZ NOSSA CARTA MAGNA SOBRE A INCLUSÃO DE NOVOS COMPONENTES CURRICULARES NA EDUCAÇÃO BÁSICA}

A Constituição da República em seu Capítulo III, Seção I, trata da Educação Nacional, o Art. 205 e seguintes estabelecem os principais parâmetros para seu desenvolvimento, vejamos:

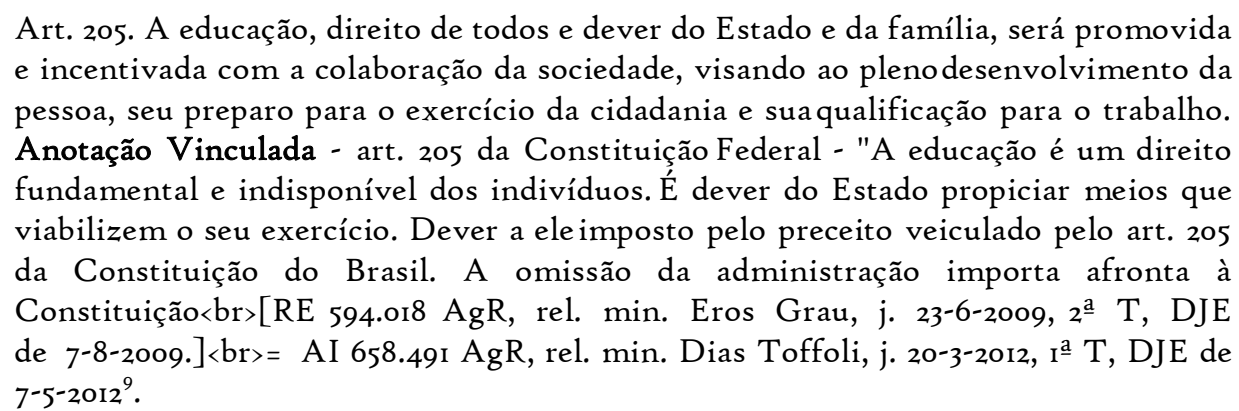

Nos termos da Carta Magna e do entendimento do Supremo Tribunal Federal

- STF, percebe-se que a Educação é um direito fundamental de todos e que o Estadoe a família têm o dever de promovê-la e fomentá-la em seu desenvolvimento. Nesse sentido,

${ }^{9}$ VIEIRA, Liszt. Cidadania e Globalização, Ed. Record, 20oo, pg. 22 
vimos que a educação tem como um objetivo preparar os jovens para o trabalho, para a vida e transformá-los em cidadãos. Com extensão de conhecimento, fica cristalino a intenção do legislador constituinte na discricionariedade, nas margensda lei, que o Gestor Público pode e deve implementar melhorias para educação.

Cumpre observar que CRFB/88, em seu art. 22, inciso ${ }^{\text {Io }} \mathrm{XXIV}$, dispõe que compete privativamente a União legislar sobre as Diretrizes de bases da Educação Nacional. Cabendo, portanto, de forma democrática e com participação dos órgãos competentes, como o Conselho Nacional de Educação, e com base no Plano Nacionalda Educação - PNE ${ }^{\text {II }}$, incluir novas disciplinas na base curricular do Ensino Fundamental, por meio de Lei Federal aprovada pela Câmara dos Deputados e Senado Federal, pois compete a União legislar privativamente sobre a temática em questão.

Nesse senário, mostraremos a seguir o entendimento do Supremo Tribunal Federal sobre o tema. $\mathrm{O}$ voto do relator, Ministro Mauricio Correia, que a maioria seguiu contra um projeto de lei estadual estabelecendo formação específica para lecionar determinada disciplina na rede pública do estado de São Paulo.

Creio que não há razão para alterar-se, neste exame do mérito, a decisão proferida na fase cautelar, pois, sem dúvida, o mencionado dispositivo violou o artigo 22, XXIV, da Carta da República, que reservou à União competência para legislar sobre diretrizes e bases da educação nacional. Sem embargo das discussões acerca do que vem a ser normas gerais nas situações de competência concorrente, no caso ressai claro que a disposição da lei está inserida no conceito de diretrizes e bases para educação nacional, tema reservado à legislação federal” - Voto do Ministro Maurício Corrêa, ADIN no. I.399/SP, p. $32^{12}$.

Nesse sentido, às vezes que foi enfrentado o tema em tela, o entendimento que prevaleceu foi de que a inclusão de novo componente obrigatório na grade curricular de qualquer das Unidade da Federação é competência privativa da União, nos termos do art. 22, inciso ${ }^{13} \mathrm{XXIV}$, da CRFB/88, sendo considerado inconstitucional o projeto da Assembleia Legislativa de São Paulo.

A luz das informações contida na Carta Maior, é perfeitamente possível incluirnova disciplina no Ensino Fundamental II, visando o preparo para a vida, o trabalho e o pleno

\footnotetext{
${ }^{10}$ Disponível em: http://www.planalto.gov.br/ccivil_03/constituicao/constituicao.htm (acesso em Io/10/2021).

${ }^{11}$ Disponível em: http://www.planalto.gov.br/ccivil_03/constituicao/constituicao.htm - Art. 22. Compete privativamente à União legislar sobre: XXIV - diretrizes e bases da educação nacional. (acesso em 10/10/2021).

${ }_{12}$ Disponível em: http://www.planalto.gov.br/ccivil_03/constituicao/constituicao.htm. Art. 22. Compete privativamente à União legislar sobre: XXIV - diretrizes e bases da educação nacional. (acesso em ro/ro/202I).
} 
exercício da cidadania.

No entanto, o legislador constituinte não foi tão claro ao definir a competênciados entes federativos nessa temática, por isso, trouxemos julgados para ratificar a forma mais segura de implementar tal projeto, pois em outros dispositivos constitucionais, como por exemplo, no Artigo 23, inciso ${ }^{13} \mathrm{~V}$, da $\mathrm{CF} / 88$, estabelece queé competência comum da União, dos Estados, DF e Municípios proporcionar os meiosà cultura à educação [...], e o Artigo 24, inciso ${ }^{14} \mathrm{IX}$, dispõe que é competência concorrente da União dos Estado e DF legislar sobre educação, cultura, ensino, desporto, ciência, tecnologia, pesquisa, desenvolvimento e inovação. O STF já se manifestou, algumas vezes, através de seus ministros, sobre o tema e o entendimentoé no sentido de que somente a União pode legislar sobre normas gerais em relação às diretrizes de base da educação nacional. Vejamos:

1. Invade a competência da União para legislar sobre diretrizes e bases da educação a norma estadual que, ainda que de forma indireta, subtrai do Ministério da Educação a competência para autorizar, reconhecer e credenciar cursos em instituições superiores privadas. [ADI 2.50I, rel. min. Joaquim Barbosa, j. 4-9-2008, P, DJE de 1912-2008. $]^{15}$

2. Competência concorrente entre a União, que define as normas gerais e os entes estaduais e Distrito Federal, que fixam as especificidades, os modos e meios de cumprir o quanto estabelecido no art. 24, IX, da Constituição da República, ou seja, para legislar sobre educação. O art. 22, XXIV, da Constituição da República enfatiza a competência privativa dolegislador nacional para definir as diretrizes e bases da educação nacional, deixando as singularidades no âmbito de competência dos Estados e do Distrito Federal. [ADI 3.669, rel. min. Cármen Lúcia, j. 18-6-2007, P, DJ de 29-6-2007. $]^{16}$

3. Lei de Diretrizes e Bases da Educação Nacional. Iniciativa. (...) Competência privativa da União para legislar sobre diretrizes e bases da educação nacional. [ADI 1.399, rel. min. Maurício Corrêa, j. 3-3-2004, P, DJ de II-6-2004.] $]^{17}$

Conforme o ensinamento do saudoso professor, José Afonso da Silva, a distribuição de competência dos Entes federados foi com base na teoria da predominância de interesse, "à União caberão aquelas matérias e questões de predominante interesse geral, nacional, ao passo que aos Estados tocarão as matérias e assuntos de predominante interesse regional, e aos municípios concernemos assuntos de interesse local ${ }^{18 \%}$.

\footnotetext{
${ }^{13}$ Disponível em: http://www.planalto.gov.br/ccivil_03/constituicao/constituicao.htm . Art. 24. Compete à União, aos Estados e ao Distrito Federal legislar concorrentemente sobre: IX - educação, cultura, ensino e desporto. (acesso em 10/10/2021).

${ }^{14}$ Disponível em:http://portal.stf.jus.br/jurisprudencia/ (Acesso em:10/10/2021)

${ }^{15}$ Disponível em: No livro Curso de Direito Constitucional Positivo

${ }^{16}$ Disponível em: No livro Curso de Direito Constitucional Positivo

${ }^{17}$ Disponível em: http://www.planalto.gov.br/ccivil_03/constituicao/constituicao.htmArt. 2I. Compete à União (caput). (acesso em 10/10/2021).

${ }^{18}$ Disponível em: http://www.planalto.gov.br/ccivil_03/constituicao/constituicao.htm. Art. 23. É da competência comum da União, dos Estados, do Distrito Federal e dos Municípios (caput). (acesso emio/10/2021).
} 
Segundo o referido ${ }^{19}$ Autor, os procedimentos para divisão de competência pela forma, conteúdo, extensão e origem seguem determinados critérios. A competência material: pode ser exclusiva, quando exclui todos os outros entes nos termos do art. 21, CF $/ 88^{20}$, somente a União pode fazer; competência comum: quando o interesse é de todos, pode ser exercida por todos os entes federativos nos

termos do Art. $23, \mathrm{CF} / 88^{2 \mathrm{I}}$; já a competência legislativa privativa: é quando enumerada à entidade própria cabendo delegação ou suplementação art. 22, § único ${ }^{22}$, competência concorrente: é quando a competência é repartida com todos, sendo que a União traça as linhas gerais e os Estados as matérias restantes Art. 24, § I ${ }^{\mathbf{0} 24}$.

Dessa forma, é possível concluir que a competência do art. 22, inciso XXIV,da CF $/ 88^{23}$, é do legislador federal para incluir um novo componente curricular no ensino básico nacional, visto que, a União criou a lei geral da educação nacional, queé a Lei 9.394/96 - LDB, cabendo os Estados e Distrito Federal suplementar para atender as necessidades regionais, tendo como parâmetro a referida Lei.

\section{DA LEI DE DIRETRIZES E BASES DA EDUCAÇÃO BRASILEIRA - LDB - LEINNo 9394/1996}

A Lei 9.394/96, por sua vez, estabelece, por meio de seu Art. 26, §10 ${ }^{24}$, que a inclusão de outros componentes curriculares obrigatórios na base Nacional Curricular dependerá de aprovação do Concelho Nacional de Educação e homologação do Ministro de Estado de Educação. Que é o intuito desse trabalho, alterar a Lei $9.394 / 96$ por meio de Lei Federal regulamentando a Lei de Diretrizes de Base da Educação, incluindo, portanto, como disciplina o Direito Constitucional no Ensino Fundamental II, para todo país, tornando

${ }^{19}$ Disponível em: http://www.planalto.gov.br/ccivil_03/constituicao/constituicao.htm. Art. 22. Compete privativamente à União legislar sobre: § único. Lei complementar poderá autorizar os Estados a legislarsobre questões específicas das matérias relacionadas neste artigo. (acesso em 10/10/2021).

${ }^{20}$ Disponível em: http://www.planalto.gov.br/ccivil_03/constituicao/constituicao.htm. Art. 24. Compete à União, aos Estados e ao Distrito Federal legislar concorrentemente

sobre: § Io . No âmbito da legislação concorrente, a competência da União limitar-se-á a estabelecer normas gerais. (acesso em ro/10/2021).

${ }^{21}$ Disponível em: http://www.planalto.gov.br/ccivil_03/constituicao/constituicao.htm. Art. 22. Compete privativamente à União legislar sobre: § único. Lei complementar. (acesso em $\mathrm{Io} / \mathrm{ro} / 2021$ ).

${ }^{22}$ Disponível em: http://www.planalto.gov.br/ccivil_03/constituicao/constituicao.htm . § io. A inclusão de novos componentes curriculares de caráter obrigatório na Base Nacional Comum Curriculardependerá de aprovação do Conselho Nacional de Educação e de homologação pelo Ministro de Estado da Educação. (acesso em 10/10/2021).

${ }^{23}$ Disponível em: http://www.planalto.gov.br/ccivil_03/constituicao/constituicao.htm (Acesso em 09/12/2021).

${ }^{24}$ Disponível em: http://wwws.sefaz.mt.gov.br/-/procon-propoe-o-ensino-dos-direitos-do-consumidor- nas-escolas-doestado (Acesso em I2/10/2021) 
obrigatório na base curricular nacional

Cumpre observar que esse projeto que visa a alteração da lei 9493/96, por meio de outra lei federal, deverá seguir o estabelecido pela Constituição Federal, vejamos:

Art. 6i. A iniciativa das leis complementares e ordinárias cabe a qualquer membro ou Comissão da Câmara dos Deputados, do Senado Federal ou do Congresso Nacional, ao Presidente da República, ao Supremo TribunalFederal, aos Tribunais Superiores, ao Procurador-Geral da República e aos cidadãos, na forma e nos casos previstos nesta Constituição. ${ }^{25}$

Dessa forma, a nova Lei deve ter status de Lei Ordinária Federal, assim como a lei 9.394/96. Devendo passar nas duas casas Legislativas, Câmara dos Deputados e Senado Federal, com a sanção do Presidente da República. A alteração deverá mencionar de maneira clara, objetiva e específica as mudanças do texto original e deforma expressa revogar aquilo que contrariar a implementação do Direito Constitucional na base curricular nacional.

Importante esclarecer que há outras alternativas, que não é o foco deste trabalho, mas que pode ser adotada paliativamente aos Estados, Munícipios e o Distrito Federal, por suas iniciativas que seria incluir a disciplina, Direito Constitucional, na parte diversificada como temas transversais, como por exemplo, o Estado do Mato grosso já implementou Direito do consumidor nas escolas. Vejamos:

Com o Projeto "Procon vai à Escola", o Procon-MT já promove diversas palestras no Estado orientando crianças, jovens e adultos quanto aos direitose deveres dos consumidores. A proposta agora é levar esta orientação para as salas de aulas e a implantação da Lei Estadual n⿳0 6.760 de 21 de março de 1996, que tornou "obrigatória a inclusão do ensino dos direitos do consumidor no currículo das escolas públicas privadas de $\mathrm{I}^{\mathrm{O}}$ e $2^{2}$ - graus do Estado de Mato Grosso" (Art. Ioㅡ), é uma alternativa. Ainda de acordo com a Lei, o Conselho Estadual de Educação, a Delegacia do Consumidor (Decon)e o Procon seriam responsáveis pela elaboração do programa curricular básico, que pode ser aplicado isoladamente ou inserida em outra disciplina (CAJUEIRO, Janayna). Procon propõe o ensino dos direitos do consumidor nas escolas do estado. Governo do Mato Grasso.2006 ${ }^{26}$.

Como nosso legislador federal tem a função de legislar sobre normas gerais da educação e já temos a referida Lei № 9.394/96 - LDB, nossa proposta é no sentidode que seja feito através de uma emenda a referida Lei, permitindo a inclusão da mencionada disciplina e que os Conselhos de Educação Estaduais e Distrital regulem o tema, com as adaptações regionais, considerando que a educação é um direito fundamental e que pertence a todos.

\footnotetext{
${ }^{25}$ Disponível em: https://www.al.sp.gov.br/repositorio/legislacao/constituicao/r989/compilacaoconstituicao-o-05.10.1989.html. (Acessado em II/II/202I).

${ }^{26}$ Disponível em: https://www.tse.jus.br/imprensa/noticiastse/2017/Agosto/pesquisaentrejovensidentificamaioriadeaptosavotarpoucosdebatempolitica?SearchableText=pesquisa\%2oentr e\%2005\%20jovens\%2016\%20a\%2017\%20anos. (Acesso em ol/1I/2021)
} 
Neste caminho vasto, o direito a uma educação de qualidade é passível de mudanças para corrigir as distorções, até mesmo porque, a sociedade é dinâmica e, constantemente, teremos adaptações. $O$ que não é permitida e, consequentemente, tornar-se-ia inconstitucional seria a regressão ou abolição do direito a uma educaçãode qualidade.

Dessa forma, percebe-se que é possível, com vontade política e visão no futuro, incluir a disciplina Direito Constitucional como um novo componente curricularobrigatório na base Nacional nos termos da Constituição Federal através de uma emenda à Lei de Diretrizes e Bases da Educação Nacional - 9.394/96.

Importante citar também que o projeto de lei no 374 de 2007, de inclusão do estudo do direito no Ensino Médio no Estado de São Paulo, o qual foi arquivado por entendimento do Executivo local, com justificativa de que somente a União poderá legislar sobre o tema, ratificando o entendimento exposto por nossa pesquisa.

Como já havia colocado, o projeto foi vetado pelo governo daquele Estado por entender que é competência privativa da União legislar sobre normas gerais da educação nacional, vejamos a justificativa.

VETO TOTAL AO PROJETO DE LEI № 374, DE 2007

Mensagem no ${ }_{13} 6 / 07$ do Sr. Governador do Estado São Paulo, in de outubro de 2007

Senhor Presidente

Tenho a honra de levar ao conhecimento de Vossa Excelência, para os devidos fins, que, nos termos do artigo $28, \S \mathrm{I}^{\circ}$, combinado com o artigo 47 , inciso IV, da Constituição do Estado, resolvo vetar, total- mente, o Projeto de lei no 374, de 2007, aprovado por essa nobre Assembleia, conforme Autógrafo no 27.303.

De iniciativa parlamentar, a propositura torna obrigatória a inclusão, no currículo escolar do ensino médio da rede pública estadual, da disciplina Introdução ao Estudo do Direito, e dá providências correla - tas. Embora reconheça os louváveis intuitos que nortearam o legislador local, não posso, todavia, dar assentimento à proposta, pelas razões a seguir enunciadas. $\mathrm{Na}$ verdade, a Constituição Federal, proclamando o cunho nacional da educação, outorga, em caráter privativo, à União, de acordo com a partilha constitucional de competências, a atribuição de definir as diretrizes e bases a serem observadas pelos sistemas de ensino, em todos os seus níveis e modalidades (artigo 22, inciso XXIV). E no exercício de tal competên-cia constitucional, aquele ente maior editou a Lei federal no 9.394, de 20 de dezembro de 1996, que dispõe sobre as Diretrizes e Bases da Educação Nacional. Por outro lado, reservou-se aos Estados competência concorrente para legislar sobre o tema (artigo 24, inciso IX, § § I음 e $2^{\circ}$, da Carta Republicana), cabendo-lhes, por esse motivo, organizar o respectivo sistema de ensino, em cooperação com os

demais entes da Federação, observadas, como de rigor, as normas gerais emanadas do Poder Central, consubstanciadas na referida lei nacional. Tendo 
presentes tais normas e diretrizes, o sistema estadual de ensino e, especialmente, os estabelecimentos de ensino definem as matérias que compõem a parte diversificada do currículo do ensino fundamental e médio, como exigência das características regionais e locais, de forma a se complementar a base nacional comum, de acordo com a norma contida no artigo 26 da Lei de Diretrizes e Bases. Nesse ponto, foram adotadas as modernas teorias do currículo, que aboliram os modelos de currículos idênticos para todas as escolas do país, denominados "guias curriculares", considerando que a organização curricular deve compreender estudos, não somente de ordem nacional, mas também, de ordem regional e local. Assim, e tendo em vista a norma do artigo 26 em questão, pode-se concluir que a alteração da parte diversificada do currículo, conforme pretende o projeto, com a inclusão da disciplina "Introdução ao Estudo do Direito", configura encargo do sistema de ensino, notadamente das escolas, às quais compete a elaboração e a execução da proposta pedagógica, atribuição própria e específica, como projeção da autonomia pedagógica e administrativa que lhes é assegurada para a concretização do princípio da gestão democrática do ensino, conforme deflui dos artigos 12, inciso I, I4 e Is da Lei $\mathrm{n}$ - 9.394, de 20 de dezembro de 1996. A propósito, a Secretaria da Educação, manifestando-se contrariamente ao projeto, esclareceu que não cabe ao Estado incluir disciplina no currículo, pois em consonância com a Lei de Diretrizes e Bases da Educação Nacional, regulamentada pelas Resoluções CEB n²/98 e $n^{\circ} 3 / 98$, do Conselho Nacional de Educação, é de competência deste órgão definir as disci- plinas do currículo escolar. Esclareceu, ainda, que noções básicas de Justiça, Cidadania, Estado e Direito são desenvolvidos de forma transversal e interdisciplinar em diversas disciplinas e, mais especificamente, na área de ciências humanas (geografia, história, psicologia, sociologia e filosofia). Por conseguinte, ao pretender determinar a integração de um componente curricular definido nos cursos de ensino médio, o legislador interfere nas atribuições conferidas às escolas, no que concerne à elaboração e execução da proposta educacional, com reflexos sobre sua autonomia pedagó gica, cujo substrato encontra-se na própria Constituição Federal, que em seu artigo 22, inciso XXIV, legitima a edição, pela União, das normas nacionais de educação, consolidadas na Lei no 9.394, de 26 de dezembro de 1996. É forçoso concluir, pois, que o projeto se mostra em descompasso com os preceitos da Lei de Diretrizes e Bases da Educação Nacional, de nítida extração constitucional, revelando-se, portanto, inconstitucional a medida nele contida. Não por outras razões, ao Projeto de lei $\mathrm{n}^{\circ} 855$, de 1999 , de conteúdo semelhante ao deste, foi necessário opor veto total, afinal mantido em recente sessão de 5 de junho de 2007, ocasião em que essa no bre Casa reconheceu a procedência dos argumentos então apresentados. Expostos os motivos que fundamentam a impugnação que oponho ao Projeto de lei $\mathrm{n}^{\mathrm{o}}$ 374, de 2007, devolvo o assunto ao reexame dessa ilustre Assembleia. Reitero a Vossa Excelência os protestos de minha alta consideração. José Serra.

\section{GOVERNADOR DO ESTADO}

Excelência o Senhor Deputado Waldir Agnello, Io Vice-Presidente no exercício da Presidência da Assembleia Legislativa do Estado. Assembleia Legislativa do Estado de São Paulo ${ }^{27}$.

Diante do exposto, vale frisar que não é pacífica a doutrina nesta temática, mas o que prevalece até então, é o entendimento do STF confirmando a competência do legislador federal para a inclusão de novos componentes curriculares na educaçãobásica nacional. Diante

${ }^{27}$ FERDINAND, Lassalle. A Essência da Constituição. 9I ed. Brasília: Lúmen Juris, 2009, p. 2I. 
do exposto, a forma correta que contempla o nosso objetivo é incluir esse componente curricular por meio da emenda à Lei 9394/96 combinando com aprovação do Concelho Nacional de Educação e homologação do Ministro de Estado de Educação.

\section{A CONQUISTA DOS JOVENS DO DIREITO DE VOTAR AOS I6 ANOS E SUAS IMPLICAÇÕES}

De acordo com a pesquisa realizada pelo Tribunal Superior Eleitoral -TSE, em 26/o6/2018, dos 3,8 milhões de adolescentes de I6 e I7 anos, apenas dois milhões iriam poder votar naquele ano, ficando de fora desse processo tão importante para o país. Cerca de i,8 milhões de Jovens deixaram de exercer a cidadania. Segundo a matéria, os especialistas afirmam que nessa idade não há interesse coletivo.

Além do mais, foi informado que a desmotivação foi mais acentuada entre osjovens de 16 e 17 anos e os de menor escolaridade reforçando a tese de que com o conhecimento da causa a tendência é melhorar cada vez mais esse interesse de participação do sistema democrático e pluralista de nosso país.

Diante disso, fica evidente a urgência de medidas que corroborem para mudança desse comportamento na juventude. Com a inclusão obrigatória da disciplina Direito

Constitucional no Ensino Fundamental II, podemos mudar a visão desse público empobrecido de informações valiosas tanto no processo democrático, como também na formação para a vida profissional desses adolescentes.

A matéria revela ainda os seguintes dados:

Há io anos, o grupo de I6 e 17 anos representava 2,1\% do eleitorado. Hoje,corresponde a 1,3\% do total. Em 2008, havia 130,4 milhões de pessoas aptasa votar no país. Em 2018, serão ao menos 147,2 milhões. O professor de ciência política da Universidade de Brasília (UnB) Ricardo Caldas acredita que os jovens só conversam sobre seus assuntos afins. Dão mais atenção aos hobbies do que aos interesses coletivos e não têm convicções políticas. De acordo com a pesquisa realizada pela empresa Opinião - Informação Estratégica (Opinião Consultoria Ltda.), o trabalho foi desenvolvido entre os dias Io de janeiro e 4 de fevereiro de 2017 , e investigou a opinião de mais de 2.6oo pessoas das mais diversas regiões do país. A pesquisa foi realizada nos municípios de Guarapuava (PR), Maceió ( $\mathrm{AL}$ ), Palmeira dos Índios (AL), Belém (PA), Curitiba (PR), Hortolândia (SP), Várzea Paulista (SP), Lauro de Freitas (BA), Alagoinhas (BA), Jaraguá do Sul (SC), Diamantina (MG), Curvelo (MG), Belo Horizonte (MG), Goiânia (GO) e Rio Verde (GO) $)^{28}$.

Cabe asseverar que a juventude vem perdendo o interesse pela política $e$

\footnotetext{
${ }^{28}$ Disponível em: http://gi.globo.com/sp/vale-do-paraiba-regiao/o-futuro-das-cidades/2015/ (Acessoem: 04/II/202I).
} 
consequentemente de cobrar os próprios direitos, por desconhecimento, isso é, o que nos reforça a ideia da inclusão do Direito Constitucional na grade curricular do Ensino Fundamental II, pois só assim traria a questão para o dia-a-dia desses futuros cidadãos.

Importante ressaltar que só começamos a interessar por determinado tema quando entendemos seus fundamentos. No caso em discursão, é o reflexo do que vem acontecendo na participação dos jovens no debate político. $O$ assunto é pouco abordado na família e, principalmente, nas escolas e quando abordado é de uma forma superficial e informal, muitas vezes de forma errada gerando ruídos e desentendimentos.

Nesse sentido, a proposta discutida neste trabalho tende a melhorar o debate sobre política, em especial, no que se referem às intolerâncias e aos radicalismos nas redes sociais que, ao invés de motivarem a participarem, muitos preferem não debaterem por receio de conflitos. Quando informamos mais pessoas, a probabilidade é ter discursões mais ponderadas.

Nessa vertente, temas como deveres, liberdades, democracia e direitos individuais e coletivos serão abordados frequentemente na formação desses jovens, permitindo esclarecer de forma ampla os princípios, conceitos e limites da participaçãode cada um na construção da democracia e cidadania de nosso país.

Nota-se que a escola é o ambiente natural e onde se dissemina a maior fonte de conhecimento científico formal, e o conteúdo inserido hoje na base nacional sobre direito e cidadania é mínimo e que impreterivelmente precisamos implementar a disciplina em questão, visto que, o esclarecimento sobre a estrutura do Estado, e a função educativa da Escola, sem sombra de dúvida, torna as pessoas mais preparadas para a vida e para conviverem com as diferenças individuais e coletivasexistente na sociedade.

\section{QUAIS AS VANTAGENS NA FORMAÇÃO DOS JOVENS COM A IMPLANTAÇÃO DO DIREITO CONSTITUCIONAL NO ENSINO FUNDAMENTAL II NA EDUCAÇÃO BRASILEIRA}

Uma das vantagens é despertar nos jovens o espírito crítico e participativo na construção de uma sociedade livre, solidária e justa. É mostrar aos futuros cidadãos os instrumentos da democracia na prática para serem utilizados conforme preceitua a constituição da República. 
Nas palavras do renomado autor ${ }^{31}$ Ferdinand Lassalle que, em sua obra "A Essência da Constituição", sustentou que esta (a Constituição de um país) seria o produto da soma dos fatores reais de poder que regem a sociedade. Se a sociedade não faz nada para promover aquilo que nossa constituição nos garante essa sociedade está fadada ao regresso.

Dessa forma, é imprescindível preparar a sociedade do futuro incluindo a disciplina Direito Constitucional formalmente e planejada na grade curricular nacional para que possamos mudar a realidade apresentada.

Há Países que investiram na educação de qualidade de seus estudantes, como por exemplo, a Islândia, Dinamarca e a Coreia do Sul que, a cada dia, destaca-se no progresso e desenvolvimento da geração de riquezas, através de tecnologias combinado com investimento na educação.

Segundo matéria divulgada no ${ }^{32}$ gi.com "o futuro das cidades", a Coreia do Sul tinha todas as desculpas para não dar certo pois era pobre e foi destruída pela guerra, porém investiu na educação e, hoje, tem Ioo\% de sua população alfabetizadae é o $3^{\circ}$ que mais investe em educação, perdendo apena para Islândia e Dinamarca. A Coreia do Sul investe cerca de 7,6 do seu Produto Interno Bruto - PIB na educação, o Brasil, antes da pandemia, estava estagnado em investimentos com apenas 5\% do PIB e, em 2020, esse percentual cai ainda mais, como se não bastassem as perdas por conta da pandemia, aulas online, internet precária, entre outros fatores desfavoráveis. Vale frisar que os mais necessitados são os que mais foram prejudicados.

É de conhecimento amplo que quem investe em educação de qualidade tem como retorno o desenvolvimento em quase todas as áreas, como por exemplo, tecnologia, infraestrutura, saúde, emprego, índice de desenvolvimento humano - IDH - entre outros.

\section{DA IMPORTÂNCIA DO PROFESSOR NESSE PROCESSO}

Vale ressaltar que, ao incluir a disciplina de Direito Constitucional no Ensino Fundamental, é imprescindível planejamentos concomitantemente à contratação de professores capacitados com formação específica, pois adaptações com professores de outras áreas, como já vivenciamos como alunos de escola pública, poderá haver prejuízos na formação desses discentes, visto que, a disciplina é complexa e exige que o profissional, no 
mínimo, seja bacharel em Direito. Caso não seja abordada de forma técnica e com professores com formação adequada, não surtirá os efeitos almejados. Nessa perspectiva, o conteúdo abordado terá adaptações para cada idadee grau de maturidade dos discentes.

O site Nova Escola publicou uma matéria referente à pesquisa realizada nos países com os melhores sistemas de educação e um dos fatores mais relevante e que precisamos observar atentamente, nesse processo, é a formação do professor, e paranão correr o risco de sermos ineficazes, apresentamos dados de quem já está tendo êxito e sucesso. Vejamos:

A importância de uma boa aula

Pesquisa nos EUA indica que a qualidade do professor tem influênciadireta no desempenho dos estudantes.

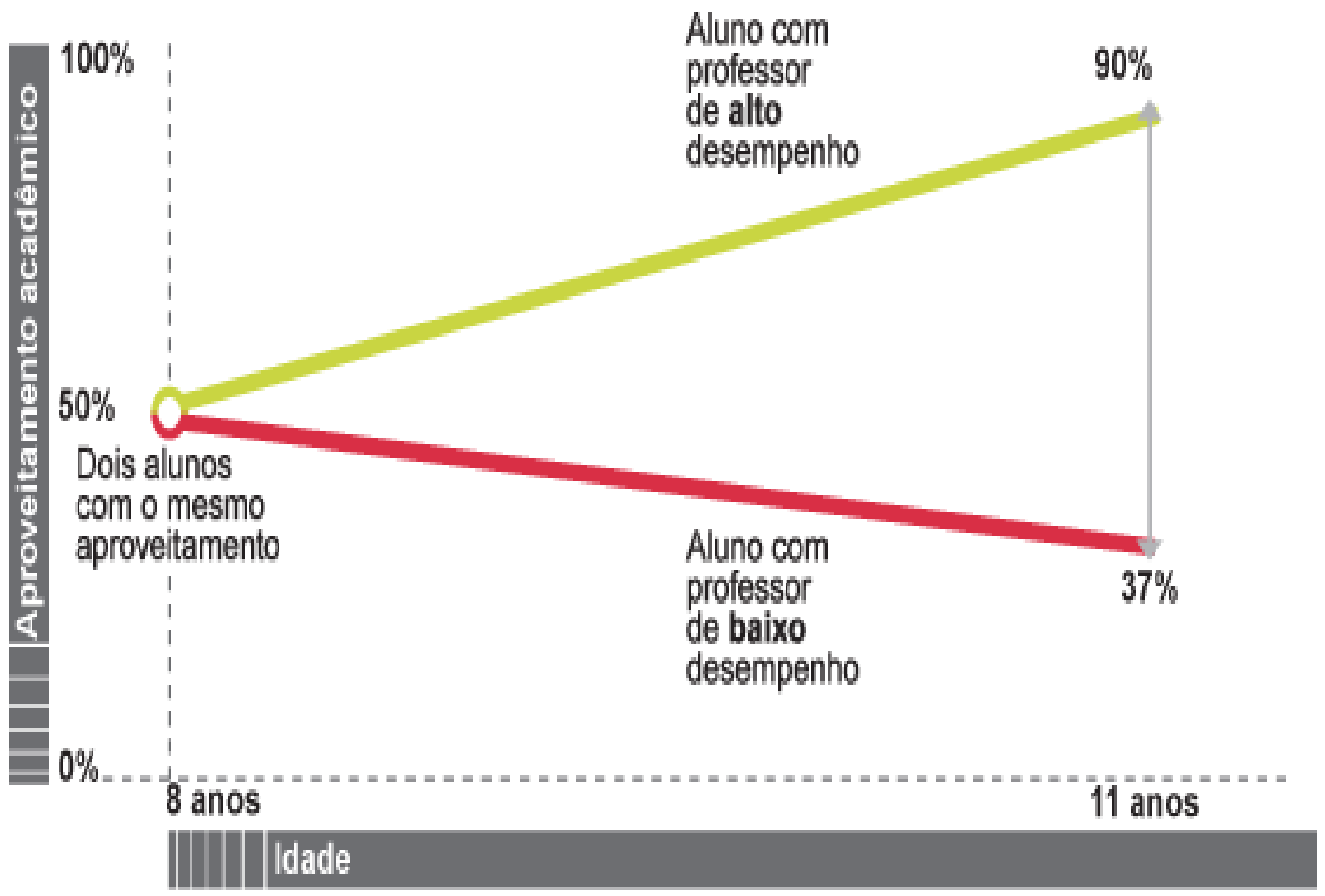

Dados do estado do Tennesseo

FONTE CUMULATVE AND RESIDUAL EFFECTS ON FUTURE STUDENT ACADEMC ACHEVEMENT 
Não por acaso, a receita dos sistemas de sucesso não abre mão de um ingrediente básico: estímulo contínuo à formação docente completa e de qualidade, seja ela inicial ou continuada. Mesmo países com desempenho intermediário nos exames internacionais - caso de Reino Unido e Estados Unidos - colheram bons resultados nas vezes em que decidiram apostar nessa receita. Para entender como também nós podemos avançar na área, NOVA ESCOLA investigou como Coréia do Sul, Finlândia e Japão, países considerados modelos em Educação, preparam seus educadores. E, nos depoimentos de três deles é possível conferir como é trabalhar em lugares que tratam o professor como prioridade.

\section{Esforço recompensado}

"Sou um profissional reconhecido como essencial para o país" (Soleiman Dias, professor de Ensino Fundamental por três anos na Coréia do Sul). Brasileiro de Fortaleza, Soleiman Dias migrou há sete anos para a Coréia do Sul para dar aulas no Iㅇ e $2^{\circ}$ anos sobre Imersão Cultural, uma disciplina sobre valores coreanos vistos por um olhar estrangeiro. A qualidade de sua formação foi determinante para conseguir o emprego: ele tem mestrado em Educação Internacional nos Estados Unidos. Em Seul, onde recebeu até uma homenagem da prefeitura pela qualidade de suas aulas, Dias goza de benefícios bem diferentes dos que teria no Brasil (e mesmo de outros trabalhadores sul-coreanos).

"Aqui, um recém-formado recebe 4 mil reais por mês. Além disso, tenho três meses de férias, muito mais do que os 12 dias a que outros profissionais têm direito. "Na Coréia do Sul, os futuros professores do Ensino Fundamental são selecionados entre os $5 \%$ dos alunos com melhor desempenho no Ensino Médio. Como os salários da carreira são bons e as vagas em universidades são poucas - apenas 6 mil por ano, a concorrência é grande. Os candidatos só garantem um lugar na graduação após terem seu histórico escolar avaliado e tirarem pontos altíssimos em uma prova. Contam também para a seleção o conhecimento em línguas e Matemática e as habilidades de comunicação, básicas para quem ensina. $O$ número de alunos que frequentam os cursos superiores atende apenas à demanda para que todos tenham um trabalho garantido 29 .

superiores atende apenas à demanda para que todos tenham um trabalho garantido ${ }^{30}$.

Diante de dados importantes que foram observados e testados como eficientes, é também nossa proposta, para que não tornamos monótonos na inclusão de uma disciplina que favorecerá a sociedade como um todo, visto que, a finalidade é proporcionar mais igualdade, mais justiça social e, principalmente, incentivos na participação de todos no processo democrático, no qual o poder emana do povo e para o povo.

\section{CONCLUSÃO}

A luz das informações contidas, vimos que o Estado Democrático de Direito

\footnotetext{
${ }^{29}$ Disponível em, https://novaescola.org.br/conteudo/2846/paises-com-melhores-sistemas-de-ensinopodem-inspirar-solucoes. (Acesso em I8/II/202I)

${ }^{30}$ Disponível em, https://novaescola.org.br/conteudo/2846/paises-com-melhores-sistemas-de-ensinopodem-inspirar-solucoes. (Acesso em I8/ II/ 202I)
} 
disponibiliza aos seus cidadãos instrumentos para aperfeiçoar a democracia. E para que ocorra a efetiva concretização, é preciso que todos conheçam direitos e deverese suas garantias. Em caso de omissão, negligência e imprudência tais instrumentos sejam acionados para as instituições constitucionais, como Ministério Público eJudiciário realizem o sistema de freios e contrapesos na preservação e consolidaçãoda República Federativa.

A cidadania está interligada com a democracia que é a participação de todos no processo de escolha dos representantes legitimados para tomarem decisões em prol de todos. Vale ressaltar, que nossa Carta Magna traz a cidadania como um dos fundamentos da República, positivado logo no artigo ${ }^{\mathrm{I}}$, inciso $\mathrm{II}^{3 \mathrm{I}}$, qual seja, a importância desse instituto para nossa democracia participativa e representativa.

Por isso, enfatizamos em nosso trabalho o exercício pleno da cidadania, pois é um instrumento fundamental e necessário, em especial, aos mais jovens que ao atingirem dezesseis (I6) anos, como demonstrado anteriormente, já possuirão conhecimentos capazede entender a relevância do exercício efetivo da democracia.

Em nossa pesquisa, percebemos que os limites impostos pela CFRFB/88 em incluir um novo componente curricular na base nacional são plenamente superados, sendo o projeto feito via emenda a LDB, Lei Ordinária Federal. Nesta senda, o legislador federal é competente para incluir novos componentes obrigatório na base curricular nacional.

Diante disso, não teremos problemas em relação a inconstitucionalidade da inclusão da disciplina Direito Constitucional. Bastando que a sociedade, o poder público e membros dos Conselhos de Educação federal, estadual/distrital e municipal mobilizem o poder legislativo federal para dar início ao referido projeto.

É notório que tal projeto terá um retorno significativo em nosso processo educacional e, em consequência disso, teremos cidadãos mais preparados para o processo eleitoral, tanto como eleitor como também como candidatos a cargospúblicos no Executivo e Legislativo.

Nosso país precisa, urgentemente, divulgar informações relevantes que mudem a vida das pessoas para melhor, diante da desigualdade social, na qual milhares necessitam dos mais básicos direitos fundamentais para sobreviver, outros, são assistidos mesmo sem ter tais direito. só corrigimos as desigualdades informando mais gente, pois assim serão "fiscais" para denunciarem irregularidades e cobrar seusdireitos e exercê-los com dignidade.

${ }^{31}$ Disponível em: http://www.planalto.gov.br/ccivil_03/constituicao/constituicao.htm.Art. Io A República Federativa do Brasil, formada pela união indissolúvel dos Estados e Municípios e do Distrito Federal, constitui-se em Estado Democrático de Direito e tem como fundamentos: II - a cidadania 
Diante de todo exposto, notamos que é de suma importância a inclusão do Direito Constitucional na vida dos adolescentes de nosso País, pois só assim teremosuma sociedade mais igualitária e próspera. Neste contexto, se implementar essa disciplina na fase ideal de formação do caráter coletivo desses jovens, poderemos mudar o histórico atual de forma paulatinamente, inclusive, com impactos também em toda sociedade, pois refletirá nas famílias de todos envolvidos. Com a implantação dessa disciplina no Ensino Fundamental II, teremos resultados significativos a médio e longo prazo na formação profissional e principalmente no que se refere ao papel decidadão que todos nós temos para aperfeiçoar nossa democracia representativa e participativa.

\section{REFERÊNCIAS}

www.al.sp.gov.br.Disponível>em:<https://www.al.sp.gov.br/repositorio/legislacao/constitui cao_27_02_202I/I989/compilacaoconstituicao-o-05.I0.1989.html.>(Acesso em 24/10/202I); www.ambitojuridico.com.br/.AMBITOJURIDICO.Disponívelem:<https://ambitojuridico.c om.br/cadernos/direito-constitucional/a-cidadania-como-pilar> (Acesso em 9/II/202I);

Brasil, Constituição (1988). Constituição da República Federativa do Brasil. Brasília, DF: Senado Federal: Centro gráfico 1988;

www.correiobraziliense.com.br.Disponívelem: <https://www.correiobraziliense.com.br/ app/noticia/politica/2018/o6/25/interna_politica,690637/maioria-dos-jovens-entre-16- e-18anos-nao-tirou-titulo-de-eleitor.shtml> (Acesso em 24/10/2021);

www.gi.globo.com. Disponível em: 〈http://gr.globo.com/sp/vale-do-paraiba-regiao/ofuturo-das-cidades/2015/> (Acesso em:10/o9/202I);

LENZA, Pedro. Direito Constitucional. 8 edição, São Paulo. Editora Método. SILVA, José Afonso da. Curso de Direito Constitucional Positivo. 28 $8^{\text {a }}$ Ed. Brasil: Malheiros, 2007, p .66; www.mundoeducacao.uol.com.br/.Disponívelem:<https://mundoeducacao.uol.com.br/sociologia /estado-democratico-de-direito.htm> (Acesso em: II/II/202I);

www.novaescola.org.br.Disponívelem:<https://novaescola.org.br/conteudo/2846/paisescom-melhores-sistemas-de-ensino-podem-inspirar-solucoes.> (Acesso em: $18 /$ II $/ 202 \mathrm{I}$ );

www2.planalto.gov.br/.Disponível>em:<http://www2.planalto.gov.br/mandatomichelte mer/acompanhe-planalto/noticias/2018/1o/entenda-o-que-e-o-estado-democratico-de direito> (Acesso em 29/10/2021);

www.secom.mt.gov.br.Disponível>em:<http://www.secom.mt.gov.br/conteudo.php?p Outras $=953 \& \operatorname{sid}=13 \& \operatorname{cid}=26425 \&$ parent $=13 \&$ total Rows Outras $=19105>($ Acesso em: $24 /$ IO202I $)$;

SILVA, José Afonso da. Curso de direito constitucional Positivo. $25^{\underline{a}}$ ed. São Paulo: Malheiros, 2005; 
SILVA, José Afonso. Curso de Direito Constitucional Positivo. Ed. 28. São Paulo: Malheiros, 200o;

www.tse.jus.br,Disponíve>em:<https://www.tse.jus.br/imprensa/noticiastse/2017/Ago sto/pesquisa-entre-jovens-identificamaioriadeaptosavotarmaspoucosdebatempolitica> (Acesso em: 24/10202I);

www.ubes.org.br. Disponível em: https://ubes.org.br/2017/desde-1988-voto-aos-ı6- anos-econquista-da-juventude/ (Acesso em: 18/10/2021);

VIEIRA. Liszt. Cidadania e Globalização. 4. Ed. Rio de Janeiro: Record, 20oo;

VIEIRA. Liszt. Cidadania e Globalização. 4. Ed. Rio de Janeiro: Record, 200o.GOYARD-FABRE, Simone. o que é Democracia? São Paulo, 2003, p. I4. 